\title{
Malaria and complex emergencies in the Eastern Mediterranean Region
}

\author{
Hoda Atta, ${ }^{1}$ Caroline Barwa, ${ }^{2}$ Ghasem Zamani ${ }^{3}$ and Robert W. Snow ${ }^{4,5}$
}

The WHO Eastern Mediterranean Region (EMR) has made substantial progress toward reducing its malaria burden since 2000. During 2007-2015, two of the five countries certified as malaria free were in the EMR (United Arab Emirates, 2007 and Morocco, 2010). Three of the 13 countries that reported zero indigenous cases in 2014 were from EMR (Iraq, Oman and Syrian Arab Republic) (1).

Efforts are still needed to: reduce the malaria burden in the six endemic countries (Afghanistan, Djibouti, Pakistan, Somalia, Sudan and Yemen); support the immediate needs for elimination in Saudi Arabia and the Islamic Republic of Iran; and prevent the re-introduction of malaria across 14 countries that have been malaria free since the 1970s. This is a challenging public health ambition at the best of times. However, it has been made increasingly difficult against the backdrop of conflict that has plagued and continues to plague many countries of the Region (2).

The civil unrest, violence and armed conflict in the Region have had an adverse impact on health services in the affected countries with deterioration because of physical damage/ destruction, reduction of human resources for programme management and implementation, and sometimes shortage of essential medicine and supplies. Despite this, the national malaria control teams, with financial support from donors and technical support from WHO and others, have worked hard to implement tailored strategies and better quality interventions and these had started to bring results, with a decreasing trend in the malaria burden in malaria-affected countries in the Region. However the recent surge in conflict situations in some countries like Afghanistan and Yemen has put these achievements at serious risk requiring concerted effort by all stakeholders to prevent setbacks and continue the progress.

A major consequence of conflict is the frequent and substantial displacement of civilian populations. Since March 2015, as armed conflict has intensified across Yemen, 2.7 million people have fled their homes within the country or to neighbouring countries. With no camps for internally displaced persons, this has resulted in a dispersed Yemeni population, making it difficult to identify and assess their vulnerability or specific needs (3). Internal conflicts in Darfur, Sudan have led to the isolation of communities which are hard to reach with routine public health services. Conflict and ethnic rivalry in the horn of Africa during the 1970s caused massive migrations of persecuted and vulnerable communities to neighbouring countries. These migrants have since become long-term residents including Ethiopian, Eritrean and Somali refugees in Djibouti and Sudan. Since the conflicts of the 1980s, there remain 300000 Afghan refugees in Pakistan. In
Kenya three refugee camps at Dadaab, designed for 90000 people, still provide semi-permanent homes for over 250000 refugees from neighbouring Somalia.

Migration to escape conflict can have health implications for the migrants and the host communities. For malaria, a fraction of migrants fleeing their homes in malaria-endemic areas of the EMR will harbour Plasmodium falciparum or $P$. vivax infections that might remain asymptomatic as a result of clinical immunity acquired while living in their home communities. If their destination within their country or across borders is an area free of malaria but still receptive to local transmission because of the presence of malaria vectors, these imported infections can result in localized epidemics. At the same time, migrants from non-malaria regions whose destination is a malaria-endemic area or who pass through endemic areas are at very high risk of severe complications from exposure to malaria parasites for the first time.

Conflict also leads to poverty. The Gross Domestic Product of Yemen, already the lowest in the Region, declined by $35 \%$ within a year of the conflict and half of those living in conflict areas have seen their livelihoods destroyed. Povertyin turn leads to economic migration and the risk of importation of malaria into malaria-free countries. Over $60 \%$ of imported malaria infections in the remaining regions of Saudi Arabia with

\footnotetext{
${ }^{7}$ Acting Director, Department of Communicable Diseases, World Health Organization Regional Office for Eastern Mediterranean, Cairo, Egypt. ${ }^{2}$ Technical Officer, Malaria, Control and Elimination, Department of Communicable Diseases, World Health Organization Regional Office for Eastern Mediterranean, Cairo, Egypt. ${ }^{3}$ Medical Officer, Malaria, Control and Elimination, Department of Communicable Diseases, World Health Organization Regional Office for Eastern Mediterranean, Cairo, Egypt. ${ }^{4}$ Senior Scientific Adviser, INFORM Project (Information for Malaria), Department of Public Health Research, KEMRI/Wellcome Trust Collaborative Programme, Nairobi, Kenya; ${ }^{5}$ Professor, Centre for Tropical Medicine \& Global Health, Nuffield Department of Clinical Medicine, University of Oxford, Oxford, United Kingdom.
} 
local transmission come from Pakistan, Sudan and Yemen.

Conflict in the Region has led to another form of migration, further increasing the risk of malaria importation. Since 2013, foreign militia, drawn from across the malaria-endemic world, have arrived in Libya (malaria free since 1973), Syrian Arab Republic (malaria free since 2004) and Iraq (malaria free since 2008), under the radar of both administrative and health authorities.

Providing the right malaria control response during the initial phases of such complex emergencies depends importantly on the origin, destination and type of migrants. Initial assessments must draw upon all available epidemiological evidence and context (4). This assembled intelligence should then be used to design locally appropriate and relevant strategies, adapted as more information becomes available. Responses need to be flexible and reactive depending on the availability of resources and partners on the ground. In that regard, WHO together with other agencies involved in malaria control in emergencies developed the interagency field handbook to set out effective malaria control responses in crisis situations. The 2013 updated edition has been revised to reflect changes in best practices, advances in technologies, availability of new tools, and revisions to WHO recommendations (5).

Surveillance in itself should remain a central pillar of intervention throughout the emergency and beyond the crisis phases. Importantly it is necessary to promptly detect, confirm parasitologically and radically treat cases to ensure complete cure and reduce severity and prevent deaths. This also includes asymptomatic infection in receptive areas targeting elimination. Prophylaxis to immunologically naïve immigrants to malaria-endemic areas mitigates the risks of very severe disease outcomes. Vector surveillance should be initiated early to define potential foci of local transmission surrounding refugee settlements and vector control strategies need to be adapted to local situation and shelters provided at refugee camps, for example, insecticide treated tarpaulins, tents or curtains (6-8). After initial crisis management, responses must be tailored to the wider host country context, supported by national strategies and policies. National strategic plans in Djibouti, Sudan, Pakistan and Yemen make special provisions for refugees and internally displaced populations.
One important aspect of all humanitarian responses is partner coordination, without which-many countries in the Region would not have managed any form of malaria control during their humanitarian crises. A large number of nongovernmental agencies have worked alongside $\mathrm{WHO}$ to provide a coordinated response to malaria in these complex emergencies. The transition to a post-conflict, national government ownership, management and stewardship is not always smooth (9). As with all aspects of humanitarian crises, international funding and coordination are greatest whilst they remain headline news. Post-conflict international support is not always addressed during the acute planning stages.

Two things remain clear, a region free of malaria would militate against the need for emergency malaria responses because of conflict so malaria elimination should continue as a regional priority even during these difficult times. More importantly, a region free of conflict would provide an opportunity to reach the global commitments on the sustainable development goals by 2030, including ending the malaria epidemic and having a region free of malaria.

\section{References}

1. Eliminating malaria. Geneva: World Health Organization; 2016 (WHO/HTM/GMP/2016.3)

2. Social determinants of health in countries in conflict: a perspective from the Eastern Mediterranean. Cairo: World Health Organization Regional Office for the Eastern Mediterranean; 2008 (WHO Regional Publications, Eastern Mediterranean Series; 32)

3. OCHA: United Nations Office for the Coordination of Humanitarian Affairs. Yemen [webpage] (http://www.unocha. org/yemen, accessed 10 April 2016).

4. Promoting innovation and evidence-based approaches to building resilience and responding to humanitarian crises. London: Department of International Development; 2012 (https://www.gov.uk/government/uploads/system/uploads/attachment_data/file/67438/prom-innov-evi-basappr-build-res-resp-hum-cris.pdf, accessed 24 April 2016).

5. Malaria control in humanitarian emergencies an inter-agency field handbook. Geneva: World Health Organization; 2013.
6. Bouma MJ, Parvez SD, Nesbit R, Winkler AM. Malaria control using permethrin applied to tents of nomadic Afghan refugees in northern Pakistan. Bull World Health Organ. 1996; 74(4):413-21.

7. Hewitt SE, Farhan M, Urhaman H, Muhammad N, Kamal M, Rowland MW. Self-protection from malaria vectors in Pakistan: an evaluation of popular existing methods and appropriate new techniques in Afghan refugee communities. Ann Trop Med Parasitol. 1996 Jun;90(3):337-44.

8. Graham K, Mohammad N, Rehman H, Nazari A, Ahmad M, Kamal M, et al. (2002). Insecticide-treated plastic tarpaulins for control of malaria vectors in refugee camps. Med Vet Entomol. 2002 Dec;16(4):404-8.

9. Guha-Sapir D, Ratnayake R. Consequences of ongoing civil conflict in Somalia: Evidence for public health responses. PLoS Med. 2009 Aug;6(8):e1000108. 